\title{
PRODUÇÃO CIENTÍFICA EM CONTABILIDADE GERENCIAL: ESTUDO BIBLIOMÉTRICO EM UM CONGRESSO NACIONAL DE CIÊNCIAS CONTÁBEIS
}

\author{
Ana Karla de Lucena Justino Gomes ${ }^{1}$, Kalliny Régis Soares ${ }^{2}$ \\ ${ }^{1}$ Programa Multi-institucional e Inter-regional de Pós-Graduação em Ciências Contábeis UNB/UFPB/UFRN \\ ${ }^{2}$ Universidade Federal da Paraíba \\ ${ }^{1}$ aklucenagomes@gmail.com \\ ${ }^{2}$ kallinyregiss@yahoo.com.br
}

\section{Resumo}

O objetivo deste artigo consiste em identificar as características das publicações efetuadas sobre Contabilidade Gerencial no Congresso USP entre os anos de 2010 a 2014. Uma apreciação dos artigos foi efetuada, com base no modelo de Lunkes, Feliu e Rosa (2012). A pesquisa é empíricoanalítica, exploratória e utilizou-se de métodos estatísticos descritivos. Como principais resultados, verificam-se que as publicações em contabilidade gerencial correspondem a $23 \%$ do total, com diminuição gradativa nos cinco anos analisados. Tal resultado corrobora com pesquisas anteriores que sugerem sua perca de espaço na academia. Identificou-se crescimento da participação feminina como primeiro autor nos artigos analisados, bem como a utilização cada vez mais frequente de referências a periódicos internacionais, além da diminuição das citações oriundas de livros, evidenciando amadurecimento dos pesquisadores da área. Em contrapartida, observou-se idade média dos trabalhos referenciados considerável, 12 anos, sugerindo que os pesquisadores da área não estão concedendo a devida atenção aos novos achados, uma vez que, a contabilidade gerencial está em crescente e constante evolução. Como estratégias de pesquisa mais utilizadas encontram-se as pesquisas de levantamentos $(33 \%)$ ou trabalhos documentais (30\%). No que concerne à classificação em temas, verificou-se que as linhas de pesquisa mais abordadas são planejamento e controle, seguido de custos. Entre os temas mais frequentemente explorados estão: gestão estratégica, análise de indicadores e mensuração e avaliação de desempenho. Por fim, sugere-se que apesar das melhorias observadas, a contabilidade gerencial é uma área que necessita de uma clara personalidade para os estudos, bem como de aprofundamento metodológico.

Palavras-chave: Produção científica. Contabilidade Gerencial. Congresso USP.

\section{Abstract}

The objective of this article is to identify the characteristics of the publications made on Management Accounting in the USP Congress between 2010 and 2014. An appreciation of the articles was made, based on the model of Lunkes, Feliu and Rosa (2012). The research is empirical-analytical, exploratory and was used of descriptive statistical methods. As main results, it is verified that the publications in managerial accounting correspond to $23 \%$ of the total, with a gradual decrease in the five years analyzed. This result corroborates previous research suggesting his loss of space in the academy. It was identified the growth of female participation as the first author in the analyzed articles, as well as the increasing use of references to international journals, as well as the decrease in citations from books, evidencing 
the maturation of researchers in the area. On the other hand, it was observed a high average age of the referenced studies, 12 years, suggesting that the researchers of the area are not giving due attention to the new findings, since, the managerial accounting is in increasing and constant evolution. Most commonly used research strategies are survey surveys (33\%) or documentary studies (30\%). Regarding classification in themes, it was verified that the most studied lines of research are planning and control, followed by costs. Among the topics most frequently explored are: strategic management, analysis of indicators and measurement and performance evaluation. Finally, it is suggested that despite the improvements observed, the managerial accounting is an area that needs a clear personality for the studies, as well as of methodological deepening.

Keywords: Scientific production. Management accounting. USP Congress.

\section{Introdução}

As pesquisas científicas desempenham um papel fundamental para o desenvolvimento e aperfeiçoamento da ciência. Possuir entendimento sobre as publicações possibilita ao pesquisador uma maior capacidade de assimilação, reflexão, delineamento, arguição e análise acerca do objeto de estudo (ARAÚJO; SILVA, 2010). É sabido que a contabilidade gerencial é uma importante área da contabilidade, porém seu lugar na academia e âmbito da pesquisa diminui gradativamente (LUKKA, 2010; MERCHANT, 2010). Isto porque a contabilidade gerencial possui peculiaridades que a coloca em posição desvantajosa em comparação aos demais campos da contabilidade, como por exemplo, a dificuldade de obtenção de dados (ITTNER; LACRKER, 2001), inviabilidade da utilização de determinados métodos de pesquisa (MERCHANT, 2010), além do rigor exigido pelo modelo imposto pela academia (HOPWOOD, 2008).

Estes fatores comprometem a contabilidade gerencial, uma vez que, as chances de uma publicação nessa área nas principais revistas de contabilidade dos Estados Unidos são $90 \%$ menores do que em outros campos do conhecimento. Este fenômeno acarreta na migração de pesquisadores para outras áreas, além de desmotivar a formação de doutores em contabilidade gerencial. Consequentemente tem-se a maior presença de professores da área financeira em programas de pós-graduação e a retirada das disciplinas não-financeiras dos currículos dos cursos de contabilidade norte-americanos (MERCHANT, 2010).

Dessa forma, surge a preocupação de verificar como estão sendo desenvolvidas as pesquisas em contabilidade gerencial em âmbito nacional, propiciando a reflexão e análise das pesquisas através de um estudo bibliométrico. Segundo Cardoso, Pereira e Guerreiro (2007) este tipo de estudo propicia, através da análise das referências bibliográficas e publicações, a medição da produção do conhecimento, sendo este um método eficaz na conjectura de tendências das teorias e autores.

Portanto, estudos desta natureza, têm sido desenvolvidos na contabilidade gerencial (BEUREN; SCHLINDWEIN; PASQUAL, 2007; NASCIMENTO; JUNQUEIRA; MARTINS 2010; SALGADO-CASTILLO, 2010; SALGADO-CASTILLO, 2011; LUNKES; FELIU; ROSA, 2012; 2013; MELO; SILVA; FALK; NASCIMENTO, 2013) e servem como meio de diagnosticar como se apresenta a pesquisa na supramencionada área. Desta forma, o objetivo geral deste artigo é realizar uma investigação bibliométrica das publicações brasileiras acerca da Contabilidade Gerencial do Congresso de Controladoria e Contabilidade da Universidade de São Paulo (USP), entre os anos de 2010 a 2014. 
Sendo assim, verificar-se-á se as pesquisas atuais permanecem ainda com as mesmas deficiências encontradas nos achados anteriores. Desta maneira, ter-se-á um quadro informacional sobre o desenvolvimento, limitações e futuras perspectivas da pesquisa em contabilidade gerencial.

A pesquisa propõe descrever as principais características das referências bibliográficas, análise dos métodos de pesquisa, número de autores por artigo, número de páginas, mapeamento das regiões que mais publicaram e verificar também as áreas e os temas onde se concentram a maior parte das pesquisas em Contabilidade Gerencial de acordo com o modelo de Hesford, Lee, Van der Stede e Young (2007) e Lunkes, Feliu, Borba e Rosa (2012).

$\mathrm{O}$ estudo justifica-se no entendimento de que a ciência necessita de pesquisas capazes de gerar conhecimento substantivo, bem como de uma reflexão acerca do que está sendo produzido, de modo que seja possível revelar o arcabouço e evolução desse campo do conhecimento científico.

\section{A Pesquisa e a Contabilidade Gerencial}

A identificação da contabilidade gerencial como uma ciência social iniciou-se a partir dos anos 60 do século passado (RYAN; SCAPENS; THEOBALD, 2002). Ao passo que, no âmbito da pesquisa científica, a contabilidade gerencial difundiu-se no início da década de 1980, a partir do despontar de periódicos específicos da área (HESFORD et al., 2007) e expansão do ensino da disciplina de contabilidade gerencial nas Instituições de Ensino (LUNKES; FELIU; ROSA, 2013).

No início das pesquisas, a contabilidade gerencial esteve atrelada à teorias econômicas, mas com o passar do tempo foram sendo introduzidas, além da matemática, as ciências sociais, a exemplo de sociologia, psicologia e filosofia. Este fato contribuiu para aflorar o caráter interdisciplinar e expansão para outras áreas, propiciando credibilidade acadêmica e profissional (BALDVINSDOTTIR; NORREKLIT; MITCHELL, 2010).

Zimmerman (2001), porém, aponta como limitação à pesquisa em contabilidade gerencial o fato de possuir sustentação não econômica, referindo-se ao aspecto de que comumente, pesquisas neste campo do conhecimento são baseadas em teorias da sociologia, psicologia, filosofia etc. Luft e Shields (2002), porém, discordam ao afirmar que a ciência econômica não pode por si só atender a toda a demanda de problemas de cunho gerencial, de maneira que, no entendimento dos autores, a contabilidade gerencial pode e deve se utilizar de outras áreas do saber.

De acordo com Lunkes et al. (2012), os pesquisadores da área de contabilidade gerencial enfrentam uma série de adversidades que são refletidas no enfraquecimento de publicações. Alguns fatores, a exemplo da dificuldade de obter dados, acabam por limitar o número de trabalhos (ITTNER; LARCKER, 2001) e conduzir a migração de pesquisadores para outras áreas, a exemplo da contabilidade financeira que dispõe de dados públicos (LUNKES et al., 2012). Zimmerman (2001) discorda ao atestar que os pesquisadores não inovam, sugerindo que estes são triviais e utilizam de pouca criatividade em seus trabalhos, portanto, o estigma da ausência de dados não poderia explicar a parcimônia de pesquisas e a carência da área.

Um elemento que poderia ser apontado como justificativa para a escassez de trabalhos corresponde a presença preponderante de professores de áreas financeiras nos programas de pósgraduação. Segundo pesquisa sobre a formação de doutores em contabilidade gerencial na Espanha, existe uma diferença de aproximadamente $40 \%$ menos doutores em contabilidade gerencial em relação à formação de doutores em contabilidade financeira. Se, em longo prazo, 
esta diferença se mantiver, será possível contemplar uma formação de professores e pesquisadores em contabilidade financeira significativamente maior do que uma formação em contabilidade gerencial (LUNKES, et al., 2012). Caso esta tendência na formação de acadêmicos não seja revertida, a academia, a contabilidade e a sociedade serão prejudicadas (MERCHANT, 2010), uma vez que, "este campo do conhecimento terá dificuldade de manter níveis de excelência exigidos pela pós-graduação" (LUNKES, et al., 2012). Desta forma, a presença marcante de professores de áreas financeiras nos programas de pós-graduação pode influenciar na formação dos estudantes e direcioná-los também para esta área, abrindo uma lacuna para o aprofundamento das pesquisas em contabilidade gerencial.

Itner e Larcker (2001) evidenciam em seu estudo, a falta de continuidade nas pesquisas, acarretando em discussões superficiais acerca dos temas investigados, o que consequentemente minimiza as chances de publicações. Lunkes et al. (2012) constataram em seu estudo bibliométrico que $86 \%$ dos autores publicaram apenas um artigo no período analisado. Isto conduz a ideia de que os trabalhos de contabilidade gerencial têm menos oportunidade de ser aceitos? Há um número restrito de trabalhos nessas áreas enviados para avaliação? Ou será que a qualidade dos trabalhos não é tão boa para serem aceitos e publicados? (MERCHANT, 2010; BALDVINSDOTTIR; MITCHELL; NORREKLIT, 2010). É totalmente exequível uma investigação de elevada qualidade em Contabilidade Gerencial (MAJOR, 2009), deve-se, no entanto, atentar para alguns pontos cruciais, a exemplo das referências utilizadas para desenvolvimento da pesquisa e procedimentos metodológicos aplicados.

Melo, Silva, Falk e Nascimento (2013) verificaram em seu estudo bibliométrico acerca das publicações em controladoria que $62,3 \%$ dos documentos referenciados nos artigos eram livros, sendo $56 \%$ nacionais e apenas $6,3 \%$ internacionais. Os autores sugerem que a produção científica em controladoria não está consolidada, devido à irrisória utilização de artigos de periódicos.

Além de todas essas adversidades, tem-se ainda a predominância de um padrão de pesquisa que exige uma grande quantidade de dados, formulação de modelos e aplicação de métodos estatísticos para responder a problemas emergentes (MERCHANT, 2010). Considerando que as bases de dados em pesquisas de contabilidade gerencial necessitam ser produzidas, principalmente a partir do método survey, demandando tempo e recursos financeiros, acabam por se tornarem inviáveis (ITTNER; LACKER, 2001; 2002; HOPWOOD, 2007; 2008). Desta forma, é necessário precaução na avaliação dos trabalhos de contabilidade gerencial para que não possam ser apreciados conforme as demais áreas da contabilidade, no que diz respeito ao método e forma de apresentação (LUNKES, et al., 2012).

\section{Estudos anteriores}

O presente tópico identifica estudos anteriores que discorram acerca da pesquisa em contabilidade gerencial e/ou produção científica em contabilidade gerencial. Para isto, faz-se necessário a escolha do banco de dados, a seleção de itens e análise sistêmica (ROSA; ENSSLIN; ENSSLIN, 2009).

Optou-se por analisar os artigos presentes na base de dados SciELO (Scientific Electronic Library Online), por critérios de acessibilidade e conveniência. A busca dos trabalhos se deu pelo uso das palavras-chaves, a saber: "Management Accounting", "Contabilidad de Gestión" e "Contabilidade Gerencial". Em seguida, foi efetuada uma análise dos resumos dos artigos encontrados e selecionados aqueles que encontravam-se alinhados com o tema da literatura, em 
pesquisa e produção científica em contabilidade gerencial, perfazendo um total de 9 artigos. No Quadro 1 pode-se verificar os autores e uma sucinta descrição de cada pesquisa.

Quadro 1 - Estudos sobre a pesquisa e produção científica em contabilidade gerencial

\begin{tabular}{|c|c|}
\hline Autores & Breve descrição dos estudos \\
\hline $\begin{array}{l}\text { Beuren, } \\
\text { Schlindwein e } \\
\text { Pasqual, } \\
2007\end{array}$ & $\begin{array}{l}\text { Buscou traçar um perfil da pesquisa em Controladoria nos trabalhos publicados em anais } \\
\text { do EnANPAD e Congresso USP de Controladoria e Contabilidade. Dentre os resultados } \\
\text { encontrados, observou-se um pequeno volume de trabalhos publicados sobre o tema } \\
\text { quando comparado a outros. }\end{array}$ \\
\hline $\begin{array}{l}\text { Frezatti, } \\
\text { Nascimento e } \\
\text { Junqueira, } \\
2009\end{array}$ & $\begin{array}{l}\text { Analisa o desenvolvimento conceitual da Contabilidade Gerencial levando em conta suas } \\
\text { peculiaridades e influências possíveis. Destaca-se que a área necessita de uma clara } \\
\text { personalidade para as pesquisas, bem como de aprofundamento metodológico. }\end{array}$ \\
\hline Major, 2009 & $\begin{array}{l}\text { Faz-se uma reflexão sobre a evolução da investigação na contabilidade gerencial , bem } \\
\text { como uma análise dos principais paradigmas teóricos subjacentes à pesquisa conduzida } \\
\text { nos Estados Unidos e na Europa. Evidencia a Europa, como o continente com os maiores } \\
\text { avanços na investigação do tema em questão. }\end{array}$ \\
\hline $\begin{array}{l}\text { Nascimento, } \\
\text { Junqueira e } \\
\text { Martins, } \\
2010\end{array}$ & $\begin{array}{l}\text { Analisou-se as características epistemológicas da produção acadêmica da pesquisa em } \\
\text { contabilidade gerencial no Brasil, por meio da inspeção dos artigos publicados nos anais } \\
\text { do ANPCONT, USP e ANPAD. Dentre os achados, destaca-se a baixa utilização de } \\
\text { referências que abordem as teorias da contabilidade gerencial, baixa incidência de } \\
\text { referências a artigos publicados em periódicos internacionais e alta idade média dos } \\
\text { trabalhos citados, } 10 \text { anos. }\end{array}$ \\
\hline $\begin{array}{c}\text { Salgado-Castillo, } \\
2010\end{array}$ & $\begin{array}{l}\text { Evidencia um panorama geral da evolução da pesquisa em contabilidade gerencial e a } \\
\text { presença deste tipo de pesquisa dentro do contexto Iberoamericano. Identifica que os } \\
\text { esforços de pesquisa em Contabilidade Gerencial Iberoamericana têm sido } \\
\text { particularmente impulsionados pela Espanha. }\end{array}$ \\
\hline $\begin{array}{c}\text { Salgado-Castillo, } \\
2011\end{array}$ & $\begin{array}{l}\text { Teve como objetivo, caracterizar e descrever as publicações sobre contabilidade } \\
\text { gerencial Iberoamericana no período de } 1998 \text { a } 2008 \text {. Apontou, dentre outros resultados, } \\
\text { uma baixa produção sobre contabilidade gerencial e sugere como causa deste fato a } \\
\text { influência dos meios de divulgação. }\end{array}$ \\
\hline $\begin{array}{l}\text { Lunkes, Feliu e } \\
\text { Rosa, } \\
2012\end{array}$ & $\begin{array}{l}\text { Realizou-se um estudo comparativo sobre contabilidade gerencial entre a Espanha e o } \\
\text { Brasil, através da análise de } 666 \text { artigos publicados em revistas brasileiras e espanholas. } \\
\text { No que concerne à classificação das pesquisas por tema, o Brasil possui maior } \\
\text { concentração nas discussões sobre planejamento e controle, ao passo que na Espanha em } \\
\text { mensuração e avaliação de desempenho. }\end{array}$ \\
\hline $\begin{array}{l}\text { Melo, Silva, Falk e } \\
\text { Nascimento, } \\
2013\end{array}$ & $\begin{array}{l}\text { Verificou-se as características da publicação definitiva sobre controladoria, nos artigos } \\
\text { publicados nos periódicos brasileiros avaliados pela CAPES. No que diz respeito aos } \\
\text { resultados alcançados, pode-se destacar a baixa utilização de periódicos internacionais } \\
\text { como referências e maior utilização de livros nacionais, sugerindo a não consolidação da } \\
\text { pesquisa em controladoria. }\end{array}$ \\
\hline $\begin{array}{l}\text { Lunkes, Feliu e } \\
\text { Rosa, } \\
2013\end{array}$ & $\begin{array}{l}\text { Analisou-se os problemas e métodos de pesquisa aplicada em estudos de contabilidade } \\
\text { gerencial na Espanha e no Brasil e comparou-as a estudos em revistas anglo-saxônicas. } \\
\text { Os resultados mostram que os trabalhos em contabilidade gerencial não ocupam posição } \\
\text { de destaque nas publicações analisadas. }\end{array}$ \\
\hline
\end{tabular}

Fonte: Elaboração dos autores (2015)

De um modo geral pode-se verificar nos trabalhos resultados congruentes, como por exemplo, o fato de que as pesquisas elaboradas na temática contabilidade gerencial necessitam de aprofundamento metodológico. Outro ponto concernente em algumas das investigações contempladas, diz respeito a não utilização de referências internacionais, bem como artigos publicados em periódicos, uma vez que, a preferência dos autores está na citação de livros 
nacionais. Por fim, pode-se destacar também a falta de uma teoria que possa assistir a elaboração dos trabalhos, ou seja, "a Contabilidade Gerencial precisa de uma personalidade, "uma cara", seja ela qual for” (FREZATTI; NASCIMENTO; JUNQUEIRA, 2009, p. 22).

\section{Abordagem Metodológica}

O presente estudo caracteriza-se como empírico-analítica, exploratória e quantitativa, tendo em vista a utilização de métodos estatísticos descritivos. A fim de alcançar ao objetivo da pesquisa, que consiste em uma investigação bibliométrica das publicações brasileiras acerca da Contabilidade Gerencial, optou-se por analisar os trabalhos publicados nos anais do Congresso de Contabilidade e Controladoria da USP. A escolha do evento científico se deu pela contribuição deste para o ensino e a pesquisa em contabilidade no Brasil. Sabe-se que a Faculdade de Economia, Administração e Contabilidade da Universidade de São Paulo (FEA/USP) sediou o primeiro núcleo de pesquisa contábil no país nos moldes americanos. Além disso, foi a faculdade pioneira ao instituir, nos anos 1970, a Pós-Graduação Stricto Sensu em Controladoria e Contabilidade, onde, um pouco mais tarde, em 1978, implantou o Programa de Doutorado em Ciências Contábeis na FEA/USP, pioneiro e único com alunos em nosso País (PELEIAS, SILVA, SEGRETI; CHIROTTO, 2007).

Optou-se por analisar um evento científico e não trabalhos publicados em periódicos, com a intenção de avaliar "pesquisas brutas", uma vez que, de um modo geral, após a exposição do trabalho no congresso, os pesquisadores buscam introduzir as críticas recebidas, aprimorar o artigo e enviam-no para avaliação em algum periódico científico (BENAVENT; ALCAIDE; DASIT; MOLINA; ZURIÁN, 2009).

Dessa maneira, realizou-se a consulta dos artigos, no site do Congresso USP, através do tópico "anais", durante o período de 2010 a 2014, perfazendo um total de 510 trabalhos publicados. Para composição da amostra, foram selecionados os artigos que compunham a área temática "Controladoria e Contabilidade Gerencial", totalizando 117 artigos a serem examinados.

No que diz respeito à classificação dos artigos de acordo com os métodos de pesquisa foi empregada a abordagem de Hesford et al. (2007) e Lunkes et al. (2012), descritos no Quadro 2. No que concerne à classificação dos artigos conforme as linhas e temas de pesquisa abordados, utilizou-se, também, os trabalhos de Hesford et al. (2007) e Lunkes et al. (2012).

Quadro 2 - Classificação e métodos de pesquisa
\begin{tabular}{|c|l|}
\hline Métodos de Pesquisa & \multicolumn{1}{c|}{ Definição } \\
\hline Analítica & $\begin{array}{l}\text { Envolve o estudo e avaliação aprofundados de informações disponíveis na } \\
\text { tentativa de explicar o contexto de um fenômeno. }\end{array}$ \\
\hline Arquivo/documental & $\begin{array}{l}\text { Envolve a utilização de informações que ainda não tiveram um tratamento } \\
\text { científico. }\end{array}$ \\
\hline Caso & $\begin{array}{l}\text { Envolve a investigação de fenômenos, inclusive pessoas, procedimentos e } \\
\text { estruturas em uma única organização. }\end{array}$ \\
\hline Experimental & $\begin{array}{l}\text { Envolve a manipulação e tratamentos na tentativa de estabelecer relações de } \\
\text { causa-efeito nas variáveis investigadas. }\end{array}$ \\
\hline Campo & $\begin{array}{l}\text { Envolve a investigação de fenômenos, inclusive pessoas, procedimentos e } \\
\text { estruturas em duas ou mais organizações. }\end{array}$ \\
\hline Framework & Envolve o desenvolvimento de um novo conceito, de novas perspectivas. \\
\hline Revisão & $\begin{array}{l}\text { Envolve basicamente síntese e revisão de literatura já conhecida. } \\
\text { Envolve a investigação de um grupo de pessoas, geralmente realizado via a }\end{array}$ \\
\hline Levantamento & \\
\hline
\end{tabular}


\begin{tabular}{|c|l|}
\hline Outros & Não se enquadra em nenhum dos outros métodos. \\
\hline
\end{tabular}

Fonte: Lunkes et al., 2012, p. 172.

Após a análise dos 117 artigos publicados, identificaram-se linhas de pesquisa, que foram agrupados em 3 clusters, a saber: (a) Custos: Engloba os temas Contabilidade de Custos, Custos gerenciais, Estudos e práticas de custos e Gestão estratégica de custos; (b) Planejamento e Controle: Conglomera os temas, orçamento, mensuração e avaliação de desempenho, controle organizacional e planejamento tributário; (c) Outros: Concentra todos os demais temas que não estão evidenciados nos tópicos anteriores, tais como: Sistemas de informação, teoria da contingência, gerencial estratégica, análise de indicadores financeiros, entre outros.

Os critérios considerados no procedimento de análise geral dos artigos concentram-se especificamente em parâmetros bibliométricos e de formato dos artigos, de maneira que não será julgada a qualidade dos artigos publicados.

Foram observados as seguintes características gerais da produção científica: o número de artigos publicados em cada edição do congresso, número de páginas por artigo. No que diz respeito aos autores: número de autores por artigo, sexo, formação e instituição de ensino a qual pertencem o primeiro autor da pesquisa. Relativo às referências: o número de referências por artigo, o percentual de referências que são periódicos, livros, anais ou eventos, teses ou dissertações e outras fontes. Quanto às Instituições de Ensino Superior (IES): IES que efetuaram maior número de publicações e natureza das IES. Adicionado a isto, identificou-se também as regiões que mais efetuaram publicações.

\section{Resultados e discussão}

\subsection{Características Gerais da Produção Científica em Contabilidade Gerencial}

Inicialmente, analisou-se as características gerais da produção científica em Contabilidade Gerencial do Congresso USP de Controladoria e Contabilidade, identificando aspectos relativos, ao número de páginas, às referências, aos autores, dentre outros.

No que diz respeito ao total de artigos publicados na área temática "Controladoria e Contabilidade Gerencial", verificou-se que estes representam 23\% em relação ao total de artigos publicados no congresso.

Pode-se verificar que o ano que houveram mais publicações em controladoria e contabilidade gerencial, foi o ano de 2010 e 2014, ambas com a mesma quantidade (29 artigos), ao passo que 2013 correspondeu ao ano em que menos publicações ocorreram ( 8 artigos). Porém, quando comparado o percentual de publicações em controladoria e contabilidade gerencial em relação ao total de publicações no congresso, observa-se a diminuição no decorrer dos anos. Este resultado corrobora com o estudo de Lunkes et al. (2012) e Salgado-Castillo (2011) que destacam a baixa inserção da contabilidade gerencial, demonstrando comportamento semelhante à realidade norte-americana.

Em relação ao tamanho dos artigos, a média geral do número de páginas por artigo corresponde a 15,65, sendo o ano de 2013 aquele que apresentou menor média $(14,25)$ e 2014 o que apresentou a maior média $(16,72)$. Os pontos mínimo e máximo identificados correspondem a 9 e 18, respectivamente. Essa análise fornece uma informação relevante a partir da reflexão que pode ser feita a respeito da limitação de páginas exigidas. Dantas, Silva, Santana e Vieira (2011), identificaram, por exemplo, em sua pesquisa, que a média dos artigos publicados na 
Revista Contabilidade e Finanças evoluíram entre 2001 e 2008, de 15,3 para 13,6, ao passo que a média da The Accounting Review, no mesmo período, aumentou de 21,7 para 31,3 páginas por artigo, evidenciando a discrepância da realidade brasileira com a estadunidense. Tais informações conduzem a reflexão de que a limitação de páginas poderia restringir as discussões das pesquisas, o que poderia comprometer o aprofundamento de um determinado tema.

\subsubsection{Análise das Referências Bibliográficas}

No que diz respeito às referências utilizadas nos artigos publicados, identificou-se que a maior parte das citações em todo o período analisado concentra-se em livros e periódicos, sendo os livros a fonte de citação mais utilizada. Essa informação corrobora com o estudo de Cardoso et al. (2007), porém diverge do estudo de Araújo e Silva (2010) que demonstra um maior número de periódicos em comparação às citações de livros.

Observa-se ainda que, apesar do número de citações oriundas de livros superarem todas as outras no total geral, há uma diminuição gradual ao longo dos anos na utilização da referida fonte de referência. Em contraposição, verifica-se que há crescimento no percentual das citações do tipo periódico e que há sobreposição dos internacionais em relação aos nacionais, evidenciando maior amadurecimento dos pesquisadores quanto à literatura estrangeira. Tal resultado está em desacordo com a pesquisa de Melo et al. (2013), que ressalta a baixa utilização de periódicos internacionais como referências e maior utilização de livros nacionais.

No que diz respeito a teses e dissertações, constata-se uma diminuição ao longo dos anos deste tipo de citação. Este dado corrobora com a pesquisa de Nascimento et al. (2010), que considera este fato inusitado, pois esperava-se um número um pouco mais expressivo de referências à teses e dissertações, devido ao aumento ocorrido nos programas de pós-graduação em ciências contábeis no Brasil.

Há um número tanto quanto considerável de referências a anais e eventos científicos, sendo predominantemente àqueles de cunho nacional. Entre as outras fontes citadas estão, principalmente normas e sites, assim como working papers e trabalhos monográficos.

É importante destacar que uma considerável parcela de trabalhos analisados utiliza uma grande quantidade de citações às Leis e Normas, gerando dúvidas quanto a estes fazerem parte do grupo controladoria e contabilidade gerencial, visto que o principal objeto da área em questão é o usuário interno.

No tocante à idade média das referências, observou-se que, no geral as citações possuem 12 anos, ou seja, há a presença de trabalhos de mais de uma década. No ano de 2010 a média está em torno de 10 anos, em 2011 de 9 anos, em 2012 de 11 anos, e por fim, no ano 2013 e 2014 também possui média de 9 anos. De acordo com a pesquisa de Nascimento et al. (2010), uma idade média superior a 10 anos pode ser considerada alta, tendo em vista as crescentes mudanças ocorridas na área nos últimos anos, bem como a dinâmica empresarial. Este dado, segundo o autor, pode indicar que os pesquisadores da área não estão concedendo a devida atenção aos novos achados. Por fim, em relação à quantidade de referências por artigo, a média esteve em torno de 32 citações por trabalho, mantendo-se constante ao longo dos anos.

\subsubsection{Características dos autores}

No que diz respeito às características dos primeiros autores dos trabalhos analisados, verificou-se que a grande maioria é do sexo masculino (66\%). Porém, apesar da predominância 
ser do referido sexo, verifica-se que no decorrer dos anos tal cenário vem se modificando a partir da diminuição dos percentuais de participação masculina e aumento dos percentuais de participação feminina. Em 2010, por exemplo, 72\% dos primeiros autores são do sexo masculino contra $28 \%$ do sexo feminino, uma vantagem de 44\%. Em 2014 observa-se outra realidade, sendo $59 \%$ dos pesquisadores do sexo masculino em oposição a $41 \%$ dos autores do sexo feminino, correspondendo a uma diferença de apenas 18\%. Tais informações sugerem interesse crescente das mulheres em controladoria e contabilidade gerencial.

Quanto à formação dos autores, verificou-se que o maior número destes possui formação em Ciências Contábeis (68\%), seguido de Administração (19\%), ao passo que os outros 14\% são compostos por pesquisadores nas áreas da Economia, Engenharia Civil, Ciências da Computação, Psicologia e Informática. No que concerne ao nível de escolaridade, identificou-se que $44 \%$ dos autores analisados possuem doutorado e $42 \%$ mestrado, retratando o alto nível dos pesquisadores, uma vez que, $2 \%$ possuem pós-doutorado, enquanto $9 \%$ e $4 \%$ correspondem a graduação e especialização, respectivamente.

Quanto ao número de autores por artigo, tem-se que 36\% corresponde à quantidade de trabalhos que possuem 2 autores, 28\% equivale àqueles com 3 autores, 25\% com 4 autores, 8\% com um único autor e apenas 3\% com 5 autores. Dessa forma, prevalece os trabalhos com 2 e 3 autores, uma vez que, as publicações conjuntas, teoricamente, são mais facilmente desenvolvidas devido à contribuição de mais de um pesquisador. Tal resultado corrobora com a pesquisa de Araújo e Silva (2010) que também identifica a predominância de pesquisa com 2 autores.

\subsubsection{Características das Instituições de Ensino superior analisadas}

Quanto à natureza das instituições nas quais os autores se encontram vinculados, $84 \%$ são IES públicas, ao passo que, apenas $16 \%$ equivalem a IES privadas. Tal dado pode ser justificado pela predominância de programas de mestrado e doutorado em IES Públicas, bem como o incentivo que é fornecido à pesquisa por meio de programas de iniciação científica.

No que diz respeito à localidade das instituições, de modo geral a região Sudeste apresenta maior número de publicações $(38 \%)$ com pequena vantagem em relação à região Sul (34\%), seguidas da região nordeste e centro-oeste, com $23 \%$ e 4\%, respectivamente. É importante destacar que não houve nenhuma contribuição advinda da região norte, bem como ressaltar a participação de uma Instituição estrangeira, advinda da Espanha, Universitat de València.

Analisou-se também as IES que efetuaram maior número de publicações, sendo em ordem decrescente as seguintes: Universidade Regional de Blumenal (14\%), Universidade de São Paulo (12\%), Universidade Federal da Bahia (8\%), Universidade Federal do Paraná (7\%), Universidade Federal do Ceará (6\%) e Universidade Presbiteriana Mackenzie (6\%). Unidas, estas seis Instituições representam $52 \%$ do total de todas as publicações em controladoria e contabilidade gerencial do congresso, durante o período analisado.

O primeiro lugar ocupado pela Universidade Regional de Blumenal pode ser justificado pelo fato de que os programas de mestrado e doutorado em Ciências Contábeis desta IES, possui a Controladoria como área de concentração. Além disto, entre os grupos de pesquisa do programa estão: pesquisas em controladoria e sistemas de informações, pesquisas em controle gerencial e pesquisas em técnicas de análise contábil e gerencial. 


\subsection{Classificação dos artigos de acordo com os métodos de pesquisa}

Faz-se necessário compreender os métodos de pesquisa empregados nos trabalhos, de modo a conhecer como os pesquisadores da área estão utilizando-se das ferramentas metodológicas. Dentre os métodos mais utilizados, para elaboração das pesquisas destacou-se as pesquisas de levantamento (33\%), que utilizam-se da aplicação de questionários. Tão utilizada quanto a pesquisa de levantamento, também é a pesquisa documental (30\%). Tal resultado se opõe a pesquisa de Lunkes et al. (2012) que traz a pesquisa documental como uma das que raramente são utilizadas na contabilidade gerencial. Outra metodologia bastante empregada corresponde ao estudo de caso, equivalente a $23 \%$ do total de artigos analisados. Entre os métodos, relativamente pouco utilizados nas pesquisas acharam-se a pesquisa experimental, campo, revisão literária e analítica.

\subsection{Classificação dos artigos em temas}

A classificação em temas faz-se necessário, pois permite compreender quais são os assuntos mais discutidos em contabilidade gerencial ao longo dos últimos 5 anos no Congresso analisado. Identificou-se que o tema mais discutido entre os trabalhos analisados é "planejamento e controle", seguido de "custos". Verificou-se nos trabalhos enquadrados na categoria "outros", uma grande diversidade nos temas abordados, sendo aqueles mais frequentes, gestão estratégica e análise de indicadores, que se mostraram presentes em todos os anos analisados.

Corroborando com a pesquisa de Lunkes et al. (2012), entre os assuntos de maior destaque estão mensuração e avaliação de desempenho, constatando a significância do tema para literatura. Pode-se sugerir que este é um tópico consolidado na contabilidade gerencial, assim como orçamento que também obteve número considerável de publicações. Um dado que chama atenção é relativo ao tema custos que apesar da quantidade apreciável de trabalhos, durante o período de 2013 não contou com nenhuma contribuição.

A divisão em clusters propicia à contabilidade gerencial oportunidade de consolidação, de forma que, pesquisadores concentrem-se em aprimorar cada vez mais suas pesquisas e até mesmo desenvolver um método de pesquisa específico para área.

\section{Considerações finais}

Tendo em vista que a contabilidade gerencial é uma importante área da contabilidade, mas quando comparada a outras linhas de investigação, como a Contabilidade Financeira, por exemplo, não possui tanta representatividade, devido a algumas de suas peculiaridades, o presente estudo se propôs a analisar as características das publicações em controladoria e contabilidade gerencial do Congresso de Controladoria e Contabilidade da USP entre os anos de 2010 e 2014.

O trabalho buscou contribuir com a pesquisa acadêmica na medida em que demonstrou as linhas e temas de pesquisa mais abordados na área, além das características acerca dos parâmetros bibliométricos e de formato dos artigos.

Ao analisar trabalhos de cunho semelhante a este, foi possível identificar deficiências nas pesquisas em contabilidade gerencial, a exemplo da baixa utilização de periódicos internacionais como referências e maior utilização de livros nacionais, além da alta idade média dos trabalhos citados, 10 anos. Os autores mencionados no referencial teórico do presente estudo sugerem a 
não consolidação da pesquisa em controladoria, sendo esta uma área que necessita de uma clara personalidade para os estudos, bem como de aprofundamento metodológico.

De fato, observou-se na presente pesquisa, alguma das deficiências apresentadas em outros estudos, bem como, identificou-se evolução e melhorias em outros quesitos. Como principais resultados obtidos pode-se destacar:

(a) uma baixa produção sobre contabilidade gerencial correspondendo a $23 \%$ em relação ao total de artigos publicados, corroborando com as pesquisas anteriores e sugerindo que este quesito ainda não evoluiu;

(b) diminuição gradativa do número de páginas por artigo no decorrer dos anos, sugerindo a limitação das discussões, dificultando o aprofundamento em determinados temas;

(c) incidência considerável de referências a artigos publicados em periódicos internacionais e diminuição gradual ao longo dos anos na utilização de referências a livros, sendo estes dois os pontos de melhoria identificados no presente trabalho, como um sinal de evolução na área e amadurecimento dos pesquisadores em relação à literatura internacional;

(d) alta idade média dos trabalhos citados, 12 anos. Considerando que a contabilidade gerencial está em crescente evolução, esta informação pode sugerir que os pesquisadores da área não estão concedendo a devida atenção aos novos achados. Sendo assim, este deve ser um ponto a ser considerado e aprimorado pela academia;

(e) maioria dos pesquisadores com titulação a nível doutorado, predominância da formação em Ciências Contábeis. Além disso, observou-se o aumento gradativo, ao longo dos anos, da participação feminina como primeiro autor, sendo esta uma informação relevante para que futuras pesquisas possam investigar tal mudança de paradigma;

(f) predominância de participação de Instituições de Ensino Superior Públicas, bem como, maior presença de pesquisas advindas da região sudeste, sendo a Instituição que mais publicou a Universidade Regional de Blumenal;

(g) estratégias de pesquisa concentradas em pesquisas de levantamentos (33\%), ou trabalhos documentais (30\%), sinalizando a necessidade de aprofundamento metodológico nas pesquisas em contabilidade gerencial;

(h) quanto à classificação em linhas de pesquisa, verificou-se que as mais debatidas são planejamento e controle e custos, sendo os temas presentes em todos os anos analisados a gestão estratégica e análise de indicadores. Entre os outros temas que obtiveram destaque estão mensuração e avaliação de desempenho, constatando a significância deste para literatura e sugerindo ser este um tópico consolidado na contabilidade gerencial, assim como orçamento que também obteve número considerável de publicações.

Em síntese delineou-se um panorama acerca dos pontos que sofreram evolução e àqueles que permanecem carentes de atenção. $O$ presente estudo fornece informações que podem contribuir para a constante evolução e aprimoramento das pesquisas em contabilidade gerencial, delineando as futuras perspectivas da pesquisa na supramencionada área.

A limitação ao trabalho está no fato de que a análise realizada restringiu-se apenas ao Congresso USP, que por mais significativa e prestigiosa que seja sua produção científica, ainda faz-se necessário a continuidade de pesquisas complementares no tema em questão.

Adicionalmente, faz-se necessário demandar atenção especial a este campo do conhecimento, devido à possibilidade de migração de pesquisadores para outras linhas de pesquisa, influenciados pela predominância de professores das áreas financeiras em programas de pós-graduação, bem como dificuldades enfrentadas na elaboração de trabalhos. Isto, a longo prazo, poderia ocasionar na diminuição de professores nas áreas gerencial e consequentemente a 
diminuição das pesquisas na área podendo acarretar no não aprofundamento teórico de temas relevantes para a contabilidade.

Quanto à isso, sugere-se a observação em quais as reais demandas das instituições e organizações brasileiras frente às múltiplas oscilações que tem ocorrido, identificando quais as questões que podem ampliar a importância da contabilidade gerencial para a sociedade e situar sua pesquisa em um debate público. Além disso, recomenda-se maior amadurecimento metodológico nas pesquisas.

Como sugestão de pesquisas futuras, sugere-se a expansão da amostra e também uma análise comparativa com diferentes países, de modo que possa ser confrontada a realidade brasileira com a internacional, verificando as diferentes linhas de investigação, bem como características semelhantes e divergentes à estrutura do artigo.

\section{Referências}

ARAÚJO, E. A. T.; SILVA, W. A. C. Pesquisa científica em contabilidade gerencial nos EnANPADS de 2003 a 2008. Universo contábil, v. 6, n.3, p. 29-44, 2010.

BALDVINSDOTTIR, G.; MITCHELL, F.; NORREKLIT, H. Issues in the relationship between theory and practice in management accounting. Management Accounting Research, v. 21, n. 2, p. $79-82,2010$.

BENAVENT, R. A.; ALCAIDE, G. G.; DASIT, A. M.; MOLINA, C. N.; ZURIÁN, J. C. V. Fulltext publications in peer-reviewed journals derived from presentations at three ISSI Conferences. Scientometrics, v. 80, n.2, p. 409-420, 2009.

BEUREN, I. M.; SCHLINDWEIN, A. C.; PASQUAL, D. L. Abordagem da controladoria em trabalhos publicados no EnANPAD e no Congresso USP de controladoria e contabilidade de trabalhos publicados no EnANPAD e no Congresso USP de controladoria e contabilidade de 2001 a 2006. Revista Contabilidade \& Finanças, v. 18, n. 45, p. 22-37, 2007.

CARDOSO, R. L.; PEREIRA, C. A.; GUERREIRO, R. Perfil das pesquisas em Contabilidade de Custos Apresentadas no ENANPAD no Período de 1998 à 2003. Revista de Administração Contemporânea, v. 8, n. 3, p. 177-198, 2007.

DANTAS, J. A.; SILVA, C. A. T.; SANTANA, C. M.; VIEIRA, E. T. Padrões de comunicação científica em contabilidade: um comparativo entre a Revista Contabilidade e Finanças e a The Accounting Review. Revista Contemporânea de Contabilidade, v. 8, n. 16, p. 11-36, 2011.

FREZATTI, F.; NASCIMENTO, A. R. DO; JUNQUEIRA, E. Desenvolvimento da pesquisa em Contabilidade Gerencial: as restrições da abordagem monoparadigmática de Zimmerman. Revista Contabilidade \& Finanças, v. 2, n. 49, p. 6-24, 2009.

HESFORD, J. W.; LEE, S.; VAN DER STEDE, W. A.; YOUNG, M. S. Management accounting: a bibliographic study. In C. S. CHAPMAN, A. G. HOPWOOD, M. D.; SHIELDS (Orgs.), Handbook of management accounting research (Vol. 1, Cap. 1, pp. 1-26). Amsterdam: Elsevier, 2007. 
HOPWOOD, A. G. Whither accounting research? The Accounting Review, v. 82, p. 13651374, 2007.

HOPWOOD, A. G. Management accounting research in a changing world. Journal of Management Accounting Research, v. 2, p. 3-13, 2008.

ITTNER, C. D.; LARCKER, D. F. Assessing empirical research in managerial accounting: a value-based management perspective. Journal of Accounting and Economics, v. 32, p. 349-41, 2001.

ITTNER, C. D.; LARCKER, D. F. Empirical managerial accounting research: are we just describing management consulting practice? European Accounting Research, v. 11, n. 4, p. 787-794, 2002.

LUFT, J.; SHIELD, M. D. Zimmerman's contentious conjectures: describing the present and prescribing the future of empirical management accounting research. European Accounting Review, v. 11, n. 4, p. 795-805, 2002.

LUKKA, K. The roles and effects of paradigms in accounting research. Management Accounting Research, v. 21, p. 11-115, 2010.

LUNKES, R. J.; FELIU, V. R.; BORBA, J. A.; ROSA, F. S. Análise Quantitativa da Produção e da Formação de Doutores em Contabilidade Gerencial: Um Estudo no Cenário Espanhol, Revista Universo Contábil, v. 8, n. 2, p. 118-133, 2012.

LUNKES, R. J.; FELIU, V. M. R.; ROSA, F. S. DA. Pesquisa científica em contabilidade gerencial: estudo comparativo entre Espanha e Brasil. Contaduría y administración, v. 57, n.2, p. 159-184, 2012.

LUNKES, R. J.; RIPOLL-FELIU, V. M.; ROSA, F. S. DA. Estudio de las Publicaciones sobre Contabilidad de Gestión en Brasil y España. Revista de Contabilidade e Finanças da USP, v. 24, n.61, p. 11-26, 2013.

MAJOR, M. J. Reflexão sobre a investigação em Contabilidade de Gestão. Revista Portuguesa e Brasileira de Gestão, v. 8, n. 1, p. 43-50, 2009.

MELO, D. L. S. DE; SILVA, A. P. F. DA; FALK, J. A.; NASCIMENTO, R. G. Controladoria: Um estudo bibliométrico dos artigos publicados em periódicos avaliados pela Capes. Revista de Contabilidade e Controladoria,v. 5, n. 3, p. 66-82, 2013.

MERCHANT, K. A Paradigms in accounting research: A view from North America. Management Accounting Research, v. 21, n. 2, p. 116-120, 2010.

NASCIMENTO, A. R. DO; JUNQUEIRA, E.; MARTINS, G. DE A. Pesquisa acadêmica em contabilidade gerencial no Brasil: análise e reflexões sobre teorias, metodologias e 
paradigmas. Revista de Administração Contemporânea - Anpad, v. 14, n. 6, p. 1113-1133, 2010.

PELEIAS, I. R.; SILVA, G. P. DA; SEGRETI, J. B.; CHIROTTO, A. R. Evolução do Ensino da Contabilidade no Brasil: Uma Análise Histórica. Revista de Contabilidade e Finanças da USP, Edição 3- Anos de Doutorado, p. 19 - 32, 2007.

ROSA, F. S., ENSSLIN, S. R.; ENSSLIN, L. Evidenciação Ambiental: Processo Estruturado de Revisão de Literatura sobre Avaliação de Desempenho da Evidenciação Ambiental. Sociedade, Contabilidade e Gestão, v. 4, p. 4-8, 2009.

RYAN, R.; SCAPENS, R. W.; THEOBALD, M. Research Method \& Methodology in Finance Accounting. Thomson, 2002.

SAlGADO-CASTILlO, J. A. Aproximación general para el análisis de tendencias en la contabilidad de gestión en Iberoamérica. Cuadernos de Contabilidad, v. 11, n. 28, p. 19-40, 2010.

SALGADO-CASTILLO, J. A. Tendencias de investigación en contabilidad de gestión en Iberoamérica (1998-2008). Cuadernos de Contabilidad, v. 12, n. 30, p. 273-300, 2011.

ZIMMERMAN, J. L. Conjectures regarding empirical managerial accounting research. Journal of Accounting and Economics, v. 32, p. 411-427, 2001. 